\title{
IAMJ
}

INTERNATIONAL

AYURVEDIC

MEDICAL JOURNAL

ISSN: 2320-5091

Impact Factor: 6.719

\section{A LITERATURE STUDY TO UNDERSTAND PHYSIOLOGICAL CHANGES OF PRE-VENEPUNCTURE SIRAA UTTHAAN IN HEAD -NECK REGION OF PATIENT W.S.R. TO SUSHRUTA SAMHITA}

\author{
Khan Rohee Wadoodkhan \\ Assistant. Professor, Dept. of Kriya Shareer, S.V.N.H.T's Ayurved College, Rahuri, Ahamednagar, \\ Maharashtra, India
}

Corresponding Author: drruheekhan11@gmail.com

https://doi.org/10.46607/iamj1709022021

(Published online: February 2021)

Open Access

(C) International Ayurvedic Medical Journal, India 2021

Article Received: 23/01/2021 - Peer Reviewed: 08/02/2021 - Accepted for Publication: 09/02/2021

D) Check for updates

\section{ABSTRACT}

Position of patient in surgical procedures is an important assisting factor. Position of patient in minor and major surgical procedures are mentioned in Ayurveda as well as modern medical science. One of such position is mentioned in Sushrut Samhita Sharirsthan chapter 8 and Shloka number 8. This reference is about Siravedh/venipuncture procedure. Siravedh is done at Sira or vein. Before this procedure a position is given to patient by Vaidya. Patient is in specific sitting and Vaayu Purna Mukh i.e. air-filled mouth position. This study is about the correlation between specific sitting with Vaayu Purna Mukh and its expected effect on venous pressure in head and neck region. Venous pressure can be explained with the help of modern physiology. Specific sitting posture and Vaayu Purna Mukh can be correlated with forced expiratory effort with closed glottis. Its expected effect on peripheral veins of head and neck can be studied and correlated with Vaayu Purna Mukh position in Uttamaangiya Siravedh procedure or bloodletting or venipuncture procedure at veins of head and neck.

Keywords: Vaayu Purna Mukh, Shirogat/Uttamaangiya Sira Vedh, venous pressure 


\section{INTRODUCTION}

This is a literature study to understand physiology of venous blood flow, when patient has given specific position before bloodletting treatment, specifically for head and neck region. siravedh procedure of bloodletting is a surgical procedure. It requires pre- and post procedures. The reference under study is from Sushruta samhita shaarir sthaan $8 / 8$. This reference talks about specific position of body parts for making veins more prominent, engorged, easily accessible and fixed in their location. Collectively, it is called as $\mathrm{Si}$ raa utthaan. Sushruta had mentioned different positions of body parts according to venepuncture site and veins. Question is, what will be the effect of particular position of body on veins of head and neck. What physiological change will occur in venous blood flow, blood volume and venous pressure, will this change assist to bloodletting treatment in head and neck region.

Superficial veins are most suitable for bloodletting treatment. This treatment is surgical, but it requires knowledge of anatomy as well as physiology. Pre and post surgical procedures assist to major procedure that is why they are major part of surgical treatments. For bloodletting treatment, one must know anatomical position of veins, vedhya-avedhya veins, vital structures around veins, pre and post operative physiology. Vedhya sira are those which are indicated for bloodletting. Some of examples of diseases are given below to understand bloodletting treatment in head neck region.

Unmaad [insanity], Apasmaar [disease like Epilepsy], karnarog, karnashoola [ear disorders, earache], timir, akshipaak, netraroga [Partial blindness, eye ulceration, eye disorders], shiroroga [diseases of head] are some of the disease indications for bloodletting treatments from vedhya veins in head and neck region.

Pre procedure position of patient mentioned by sushrut-

In this reference ${ }^{1}$, patient seats on a place of height equal to distance between elbow and tip of little finger [aratni]. Both hands bent at elbow. Elbows are on knee. Fists are made and put below the chin. Thumbs are in fist of hands. Hands are covered with a cloth.
Ends of Cloth are in hands of a helper standing on backside of patient. Patient is now with air filled mouth. This is the position of patient mentioned by sushrut, in simple language. This posture is to make the veins prominent [sira utthaan].

After this sira utthaan, bloodletting treatment's procedure should be done on vedhya vein of head- neck region.

To understand physiological change in this position following literature review is taken from modern medical physiology. Few relevant terms are mentioned ${ }^{2,3}$. Concept of venous pressure: Venous pressure is a pressure exerted by the contained blood in veins. There are two types of venous pressure, central and peripheral. Central venous pressure is a pressure in vena cavae and right atrium. Peripheral venous pressure is a pressure in peripheral veins.

Venous pressure is not same in all veins. It is less in the body parts above the heart level. It is greater in peripheral veins than in central veins. Venous pressure is directly proportional to volume of blood in venous system.

Concept of intrapleural pressure: It is a pressure existing in pleural cavity. It is also called as intrathoracic pressure. Under physiological conditions intrathoracic pressure is always negative. At the end of normal expiration intrathoracic pressure is $-2 \mathrm{mmHg}$. This negative pressure acts as suction pump and pulls venous blood from lower part of body towards heart against gravity. Thus, this pressure is responsible for venous return. So, it is called as a respiratory pump for venous return.

Concept of forced expiratory effort with closed glottis: It is also called as Valsalva maneuver ${ }^{3}$. Valsalva maneuver is performed in different ways. This technique is named after Antonio Maria Valsalva, a seventeenth century physician and anatomist. He had used it for testing Eustachian tube patency. It is used to pop ear when Eustachian tube clogs. It is contraindicated in eardrum injury. In this case nose is pinched and mouth is closed with air. It is also used in weightlifting-breathing patterns.

Glottis is laryngeal cords or airway, see image- 01 . 
A common example of Valsalva maneuver in daily life is straining during defecation sitting in Indian toilet, Image -02 .

In the case of siraa utthaan mentioned by Sushruta, this type of forced expiratory effort with closed airway is considered. Image -02 .

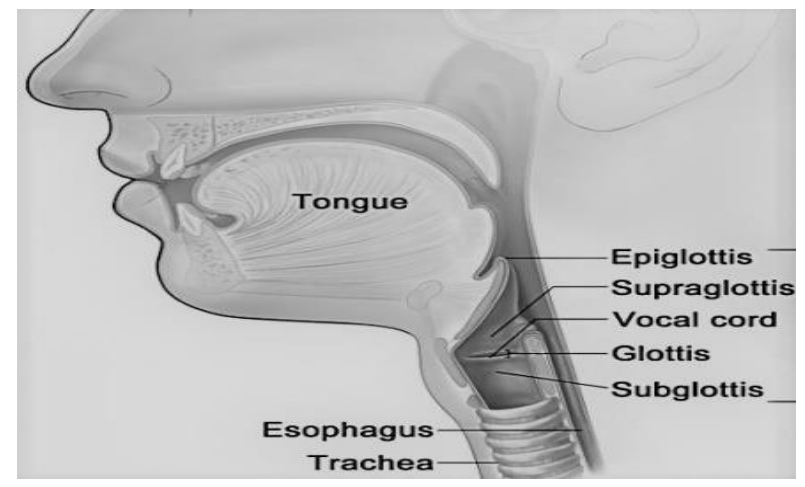

Image 1: Glottis

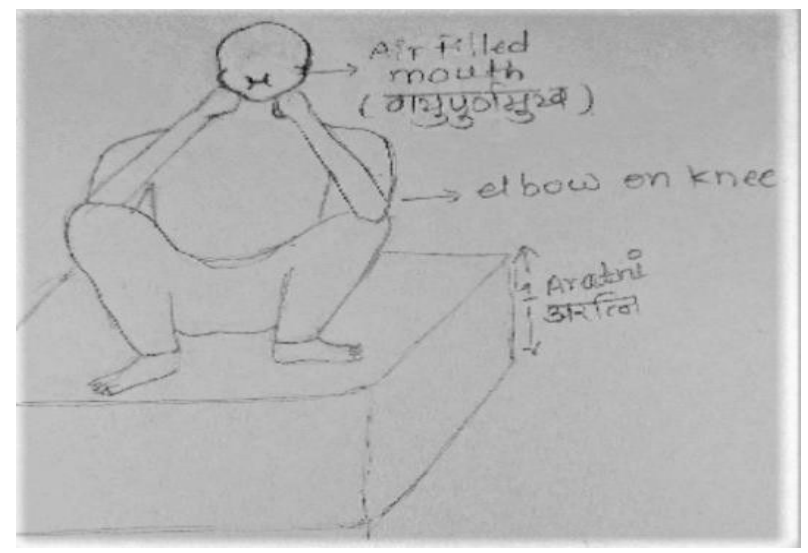

Image 2: Pre-venipuncture position of patient mentioned by sushruta, for head neck region

Simple steps to do valsalva maneuver-

- Smell deeply and then hold your breath.

- Feel that the chest and abdominal muscles are very tight and bear down as though straining to initiate a bowel movement.

- Hold this position for a short time, usually about 8-10 seconds.

- Breathe out effectively to release the breath rapidly.

- Resume normal breathing.

There are different methods and modifications to do it, few mentioned above with images.
So, deep breath is taken. The expiratory muscles of chest and abdomen are forcefully contracted while keeping glottis or laryngeal cords and trachea closed and air cannot leave the lungs. This will result in strong compression of abdomen and thorax. At the end, intrapleural pressure becomes more positive i.e. in between +20 to $+30 \mathrm{mmHg}$.

This positive intrathoracic pressure produces following effects:

1. Compression of central vein in thorax.

2. Decrease in venous return to right heart.

3. Increase in peripheral venous pressure due to accumulation of blood in peripheral veins such as veins of neck, face.

4. Decrease in central venous pressure.

During forced exalation with closed larynx, [airway is automatically closed], chest cavity has positive pressure and venous blood is not drawn towards right atrium. Blood is in peripheral veins i.e. decrease in central venous pressure, increase in peripheral venous pressure.

\section{Phases of valsalva maneuver-}

Four phases ${ }^{4}$ -

Phase 1-onset of strain- transient increase in blood pressure lasts for few seconds. Increased intrathorasic pressure, mechanical compression of aorta due to act of blowing

Phase 2- continued strain-reduced venous return to right atrium, cardiac output and systolic pressure, carotid baroreceptors inhibit vagus nerve and stimulate vasomotor center reflex tachycardia and peripheral vasoconstriction

Phase3- release phase- transient decrease in blood pressure lasting for few seconds, little change in heart rate, mechanical displacement of blood into pulmonary vascular bed, which was under increased intrathoracic pressure

Phase4- recovery phase- accumulated venous return reaches left ventricle and increased stroke volume is pumped in to constricted systemic vascular bed causing overshoot of blood pressure. Overshoot detected by carotid sinuses resulting in excitatory effect on vagus nerve leading to reflex bradycardia, 
Correlation between expected condition of peripheral veins in position of patient before bloodletting procedure at head neck veins and forced expiratory effort with closed glottis: -

The position mentioned by Sushruta and Valsalva maneuver in modern physiology is like the position of person seating in Indian style toilet and straining. The effect on veins in head and neck region should be same in these two postures.

Effect of positive intrathoracic pressure on peripheral veins [explained above] is expected effect in this siraa utthaan and bloodletting procedures. Blood is accumulated in peripheral veins of neck and face. Veins will be engorged and prominent, specifically in second phase of maneuver.

\section{DISCUSSION}

In bloodletting procedures vein should be prominent and engorged due to more blood volume, as the surgeon wants to remove an amount of venous blood from particular indicated region of body. It will assist the procedure. There should be more venous pressure. Venous pressure is directly proportional to volume of blood. If venous return to right heart is decreased, then blood will be more in peripheral veins. There will be more venous pressure in peripheral veins. At physiological level, venous pressure in the organs above the heart level is less. It should be increased with some technique before bloodletting treatments specifically in head -neck region. This low venous pressure can be increased with forced expiratoryeffort with closed glottis.

Normally, intrapleural pressure is negative which acts as respiratory pump and blood is driven from peripheral veins to right heart. In forced expiratory effort with closed glottis, intrapleural pressure becomes positive. This will result in decreased venous return to right heart i.e. decreased function of respiratory pump. It will result in accumulation of blood in peripheral veins, engorgement of veins. It is achieved in only 3-5 seconds. It should be an expected position of patient pre bloodletting procedure.

Sushruta had mentioned the use of tourniquet like cloth for sira utthaan in limbs. Tourniquet can not be used in head -neck region directly. It will threaten life of patient due to compression of vessels and stoppage of blood supply to brain as well as tracheal damage, stoppage of airway. So, the position of patient is very typical and important. Head and neck region are vital portion of body. It protects vital structures in it [Marma]. As veins are slippery structures, it is difficult to have sira utthan in region above the clavicle [jatru urdhva]. It is an important view of surgeon Sushruta, that he had well mentioned and described a position of patient for such a difficult procedure. Application of bloodletting in head neck region is difficult; siraa uttaahn in this area is difficult as it is low pressure area as compared to bloodletting in limbs. Tourniquet can not be applied so difficulty is added.

Sushruta's position brings slippery veins of patient to be fixed and prominent, blood volume is directed towards peripheral superficial veins, blood volume increases, venous pressure is raised in the veins of head neck region, expected siraa uthaan is acquired in patient.

The helper mentioned by Sushruta in this reference will be for fixing hands in position, specifiacally when patient is suffering from unmaad or such type of illness in which patient can move. If patient will move any part in this position, there are more chances of causing damage to vital structures. In such a case procedure will fail and vein will be durvedhyaa badly punctured vein, which is a complication in this case.

So, the difficulties in bloodletting from head and neck region are-

Low venous pressure area, Tourniquet can not be directly applied, veins are slippery, area includes vital structures, if patient is unmaadi, apsmaari, or suffering from similar type of illness and indication is of bloodletting, movement of patient while procedure These all are solved by Sushruta, by providing a physiological change in venous blood volume and venous pressure through a pre-procedure position of patient. It will defiantly assist to bloodletting procedure. 


\section{CONCLUSION}

Pre - venepuncutre position of patient at head -neck region mentioned in shloka of Sushrut shaarir sthan $8 / 8$ should be a forced expiratory effort with closed glottis. Physiologiacally, venous blood volume will increase, blood will accumulate in veins of head, neck and face region increasing venous pressure. There will be proper Siraa utthaan. Patient will not be able to move, to avoid durvedhya. This position of patient will defiantly assist bloodletting treatment.

\section{REFERENCES}

1. Ambikadatta shastree, sushruta, Sushrut samhita, Chaukhamba Sanskrit Sansthan, Varanasi, sanskaran 11 [1997] sharirsthan 8/8

2. Ghai, A textbook of practical physiology, jaypee brothers' medical publishers, sixth edition, 2005.page no.155-156

3. $\mathrm{k}$ sembulingam, Essentials of medical physiology, second edition 2000, page no.477

4. www.google.com

\section{Source of Support: Nil \\ Conflict of Interest: None Declared}

How to cite this URL: Khan Rohee Wadoodkhan: A Literature Study To Understand Physiological Changes Of Pre-Venepuncture Siraa Utthaan In Head -Neck Region Of Patient W.S.R. To Sushruta Samhita. International Ayurvedic Medical Journal \{online\} 2021 \{cited February, 2021\} Available from: http://www.iamj.in/posts/images/upload/430_434.pdf 